\title{
Padre Ney Brasil Pereira, profeta da misericórdia
}

Vilmar Adelino Vicente*

Fomos surpreendidos, no dia 04 de janeiro de 2017, com a morte de Pe. Ney Brasil Pereira ${ }^{1}$, um profeta e pastor, que enriqueceu a Igreja de Florianópolis e do Brasil com seus talentos musicais, conhecimentos bíblicos, mas, sobretudo, com uma profunda misericórdia exercida na pastoral carcerária e no amor aos pobres.

Neste artigo buscamos brevemente traçar o perfil de sua rica personalidade, bem como sua forte identidade com o princípio da misericórdia, cuja fonte inspiradora encontrava na sabedoria bíblica.

\section{O perfil existencial do Padre Ney Brasil Pereira ${ }^{2}$}

Acabamos de perder do nosso convívio o querido Pe. Ney Brasil Pereira. Entregamos ao Pai do céu um grande tesouro que marcou profundamente a caminhada da Arquidiocese de Florianópolis nas últimas décadas. A riqueza de sua personalidade e suas peculiaridades não pode ser resumida em poucas palavras. Apresentamos alguns destaques:

Pe. Ney, apóstolo dos presos e da pastoral carcerária, destacou-se no seu atendimento pastoral de nossa penitenciária, do presídio feminino, do nosôcomio judiciário, em Florianópolis, como também na colônia penal de Palhoça. Além disso, lutava para a articulação da pastoral dos presos em todo o Estado de Santa Catarina. Lutou mais ainda pela implementação de um sistema eficiente de recuperação prisional (APAC), a ser iniciado brevemente em Santa Catarina. Nesse contexto a Teologia da Misericórdia merecia seu empenho no enfoque bíblico e pastoral.

* Doutor em Serviço Social pela PUC-SP, São Paulo, SP. Mestre em Administração Pública pela UFSC, Florianópolis, SC. Especialista em Filosofia Política pela UFSC, Florianópolis, SC. Professor de Teologia Moral na FACASC. Presbítero diocesano da Arquidiocese de Florianópolis, SC.E-mail: vilfloripa@bol.com.br

1 Pe. Ney Pereira Brasil foi presbítero da Arquidiocese de Florianópolis, SC, mestre em Sagrada Escritura, especialista em música e coordenador da pastoral carcerária na Arquidiocese de Florianópolis e na CNBB Regional Sul IV.

2 Ver artigo de Pe. José A. Besen, que desenvolve o percurso biográfico de Pe. Ney Brasil Pereira com riqueza de detalhes: <https://pebesen.wordpress.com>. 
Pe. Ney, mestre em exegese bíblica, projetou-se como um exegeta rigoroso e competente, participando de vários grupos de tradução bíblica. A bíblia era a viga mestra de sua espiritualidade e de sua pastoral, além da marca da sua produção musical. Recentemente a edição bíblica das Paulinas mereceu dele uma revisão de várias páginas com comentários e correções.

Pe. Ney foi mestre original da música. Seu talento musical não tinha limites: música clássica, erudita, pastoral e litúrgica. Buscava sempre valorizar o conteúdo bíblico e cristológico em suas composições. A sublime música era sua paixão e nosso encanto. Como esquecer os concertos dePáscoa e de Natal em nossa catedral? Como não recordar o concerto anual na festa de Santa Cecília?

Pe. Ney, pai dos pobres, acolhia-os nas escadas e no portão da FACASC e do seminário Convívio Emaús. Os pobres eram vistos por ele como profetas de nossa realidade e destinatários do Reino. Pouco importava que incomodassem nossas casas; os pobres eram os preferidos de Jesus e do Pe. Ney.

Pe. Ney, comprometido com a formação presbiteral, esteve sempre envolvido na formação de nossos seminários. Orgulhava-se de ter colaborado na formação de mais de 600 presbíteros! Sua vida desenvolveu-se no seminário de Azambuja, no ITESC, no Convívio Emaús, na FACASC. Um formador manso, mas exigente e crítico diante do pacto de mediocridade de alunos pós-modernos com suas tendências minimalistas. $\mathrm{O}$ povo merece o melhor, por isso, não se devia perder tempo com superficialidade, repetia ele.

Pe. Ney, professor de história, que defendia como mestra da humanidade: história universal, história da América Latina, história do Brasil, história da Igreja, mereciam sua dedicação ao magistério. A história era considerada uma bússola para o discernimento da humanidade e da Igreja.

Pe. Ney, um autêntico manezinho da ilha, era devoto de Nossa Senhora do Desterro e de Santa Catarina de Alexandria, a quem dedicou um livro. Torcedor sofredor do Avaí, chegou a compor um hino a Nossa Senhora da Ressacada, sendo sua cor preferida o azul e branco. Apreciava nossos hábitos e comidas locais, assumindo como seu nossos costumes e sotaque. Amava profundamente nossa cidade e não faltava à procissão do Senhor dos Passos e de Nossa Senhora das Dores. Apesar disso não 
deixava de ir à festa de Nossa Senhora das Graças na sua amada São Francisco do Sul, berço de sua vida, no bairro Laranjeiras.

A par de sua simplicidade, Pe. Ney Brasil tinha um forte relacionamento com o mundo cultural e artístico da cidade: sopranos, barítonos, músicos de todos os instrumentos eram seus amigos e conhecidos; a todos valorizava especialmente os maestros e regentes. Não faltava aos diversos programas culturais da cidade, no TAC, no CIC, no Teatro Pedro Ivo. Acrescente-se que Pe. Ney mantinha contato com o mundo jornalístico e político, defendendo seus pontos de vistas e contribuindo com suas críticas e sugestões. ${ }^{3}$

Pe. Ney era esportista. Nadador apaixonado, ia 2 ou 3 vezes por semana a academia para nadar e se exercitar. Valorizava o corpo como templo do Espírito Santo e a saúde como dom precioso.

Pe. Ney, um teólogo pluralista. ${ }^{4}$ Embora defendesse os valores e riquezas do pensamento teológico clássico e tradicional, apreciava também uma teologia mais moderna e crítica, como a do Concílio Vaticano II e das conferências do CELAM. A última recensão crítica que elaborou foi sobre o livro de Hans Küng, teólogo suíço, sobre Jesus de Nazaré, ao qual fez significativos elogios e considerações. Como membro da Pontifícia Comissão Bíblica, em Roma, costumava dizer que as discussões e estudos daquela instituição careciam de uma abertura exegética maior.

Enfim, Pe. Ney foi um santo profeta que viveu entre nós, uma santidade marcada por: simplicidade e humildade, evitando todo o tipo de narcisismo e personalismos; caráter moral e defesa dos valores éticos do evangelho; crítica aos erros e equívocos do nosso tempo; coragem de defender posições e convicções arrojadas. (Basta lembrar a defesa da criação da diocese de Itajaí nas reuniões e assembleias do clero); fidelidade aos compromissos assumidos, especialmente na capelania das Irmãs da Divina Providência e na capelania da penitenciária (Igreja São João Batista, na Pedra Grande); regência do coral Santa Cecília, na Catedral; paixão ilimitada pela causa dos pobres e pelas vocações.

A formação presbiteral de Pe. Ney Brasil Pereira ocorreu no período pré-conciliar no seminário de Azambuja, a partir de 1941; depois

3 Basta lembrar sua insistência em propor uma nova letra para o hino oficial de Santa Catarina, uma vez que considerava o hino em vigor mais abolicionista do que catarinense.

4 O pensamento de Pe. Ney, em vários aspectos, pode ser lido em entrevista concedida ao IHU-online, em 24/07/2014. 
em São Leopoldo na Faculdade Cristo Rei, dos padres jesuítas, nos anos 50; por fim, em Roma, onde cursou teologia de 1952 a 1956, tendo sido ordenado presbítero em 25 de fevereiro de 1956.

Todavia a intensidade dos anos conciliares, no que tange a reflexão teológica, nos mais diversos campos, fez com que Pe. Ney também passasse por uma revolução copernicana de conceitos. Sutil e pontual em suas críticas, defendia os avanços da Igreja, com o decidido equilíbrio, a fim de permanecer em Cristo. Sempre esteve convicto de que o Espirito conduz à verdade plena (Jo 16,13).

Por isso, se de um lado, reagia às improvisações e radicalizações na formação do clero, que lhe causaram enormes dificuldades e sofrimentos, sob outro ponto de vista, defendia as novas intuições conciliares como a reconceitualização da noção de infalibilidade, uma linguagem adequada à modernidade e a formulação de uma teologia que respondesse aos desafios do nosso tempo, com uma nova roupagem linguística. No rastro deste horizonte foi ardoroso defensor da nova hermenêutica bíblica. "Não há outro meio de progredir senão pelo estudo da bíblia", dizia ele. Aliás, acompanhou o desenvolvimento bíblico no Brasil, desde 1947, a produção bíblica de Frei Carlos Mesters e do CEBI, bem como diversas publicações e traduções da bíblia no Brasil, em muitas das quais foi colaborador. Este legado o fez membro participante da Pontifícia Comissão Bíblica, em Roma, por longo período, onde sempre pleiteou uma abertura maior na exegese e na hermenêutica bíblica.

Todos esses aspectos the conferiam uma mente muito aberta na defesa dos valores e novos posicionamentos como: o celibato opcional; maior participação da mulher na Igreja; incremento ao ecumenismo; aprimoramento da música litúrgica; tudo numa salutar compreensão de inspiração bíblica. Isto sem deixar de valorizar muito a Doutrina Social da Igreja e, neste horizonte, a pastoral carcerária a qual se dedicou por décadas. Foi um entusiasta do pontificado do Papa Francisco e, máxime, do princípio misericórdia que analisamos a seguir.

É muito importante destacar que como músico Pe. Ney deixou-se influenciar em sua produção musical por uma teologia renovada pelo Concílio Vaticano II e sobretudo, por uma cristologia que, transcendendo o patético e o estético tradicional, se firmava nos novos horizontes da cristologia histórica, comprometida com o drama humano e a esperança dos novos céus e da nova terra. 
Pe. Ney, enfim, superou o tradicionalismo intimista e fez da misericórdia a sua grande obra pastoral, exegética e musical. A misericórdia fazia-o pulsar pari passu com o coração do Papa Francisco, condenando toda autorreferencialidade, assumindo a lógica da Escritura em favor dos pobres e excluídos. Deste modo Pe. Ney foi para nós um profeta que nos revelou o rosto de Deus em plena modernidade, na sublimidade da música, na complexidade exegética e nas pastorais sociais.

Em suma, um homem santo, com contradições, como nós, humanos, o somos! Um homem santo com pressa pelo advento do Reino de Deus!

\section{Padre Ney Brasil Pereira e o legado bíblico da misericórdia}

Apaixonado pela publicação da Misericordiae Vultus ${ }^{5} \mathrm{Pe}$. Ney não economizava elogios ao documento e seu conteúdo como revelação do rosto de Deus. O Ano da Misericórdia quis ser um sinal eficaz do agir do Pai, rico em misericórdia (Ef 2,5). Lembra que São João Paulo II nos havia contemplado com Dives in Misericordia ${ }^{6}$

Qual o significado da misericórdia no legado bíblico? Indo do hebraico (hesed) ao grego (éleos) para chegar no latim a palavra misericórdia tem profunda riqueza semântica. Lembra o Profeta Oseias (Os 6,6 ), evocado por Jesus em duas vezes, como evangelho (boa notícia). Pe. Ney destaca que a palavra misericórdia aparece na Sagrada Escritura mais de 400 vezes. $^{7}$ Assim, a misericórdia é a expressão forte da relação de Deus com o seu povo. Deste modo, os 10 mandamentos seriam orientados preventivamente pela ótica da misericórdia. Mas, reconhece Alonso Schokel, que a misericórdia vem impregnada também do sentido de lealdade de Deus pelo seu povo amado. ${ }^{8}$ A partir daí a polissemia de misericórdia tem dezenas de significações convergindo para o sentido mais profundo do termo. Seja pela vertente de hesed ou rahamim, a misericórdia é expressão de profundo amor e ternura semelhante ao amor de mãe ou mais radicalmente amor de seio materno.

\footnotetext{
Bula do Papa Francisco, publicada em 11/04/2015.

Encíclica: Deus rico em misericórdia de 30/11/1980.

Dicionário bíblico hebraico-português, São Paulo, 1997.

8 Inclusive na tradução portuguesa da bíblia hebraica, São Paulo, Séfer, 1997.
} 
A reflexão busca nesse caminho o significado maior do refrão "eterno é seu amor" do Salmo 136, onde amor e misericórdia trocam em diversas traduções bíblicas. ${ }^{9}$ Para o nosso protagonista éleos, evoca compaixão ativa pelo sofredor ou pecador, que nos leva a agir e compreender, advindo daí o Kyrie eléison e até a eleemosine (esmola). Lembra que já São Jerônimo concebia essa ótica de misericórdia para o termo hebraico e grego desvelando a composição do vocábulo, como miserere (compaixão) e cor (coração) diante do infeliz. Daí que, conclui a bíblia ecumênica no seu prólogo, "Oseias vai longe e tão fundo que o povo de Deus, ainda hoje, não pode lê-lo sem estremecer de esperança". ${ }^{10}$ Este é o significado maior de Oseias 2,21-22: "Eu me casarei contigo conforme a justiça e o direito, com misericórdia e ternura." Essa ótica de Oséias é assumida por Jesus (Mt 9,13 e 12,7), ao afirmar que Deus não quer sacrifícios, mas amor, bondade, benevolência e solidariedade. A riqueza polissêmica de misericórdia pode ser encontrada no dicionário de teologia do AT. ${ }^{11}$

Completando essa reflexão, Pe. Ney lembra a contribuição de Cesáreo de Arles, do século VI, que afirma a misericórdia como palavra suave que todos desejam recebê-la, mas poucos querem dá-la. Ora, como temos coragem de desejá-la e fingimos quando não damos a misericórdia aos pobres. "Dai a misericórdia terrena e recebereis a celeste". ${ }^{12} \mathrm{E}$, conclui Pe. Ney, guarda a misericórdia (hesed) e o direito (mispat) e espera sempre no teu Deus (Os 12,7).

Descortinando o Novo Testamento, Pe. Ney percebe a identidade de Mateus com o Profeta Oseias e também com Miqueias, destacando a misericórdia de Jesus com os pecadores, diante dos rigores da lei. Justifica Jesus no banquete com Levi (Mt 9,13): Deus quer misericórdia e não o rito pelo rito. Justificando atitudes dos discípulos (Mt 12,7), Jesus também tem atitudes duras diante da hipocrisia (Mt 23,23) e postula a prática do direito e da misericórdia. Destaca ainda Pe. Ney, no evangelho de Marcos: "Amar ao próximo como a ti mesmo supera todos os holocaustos e sacrifícios" (Mc 12,33). E arremata o elogio de Jesus ao escriba: "Não estás longe do Reino de Deus" (Mc 12,34). Já em Lucas

9 Inclusive na tradução portuguesa da bíblia hebraica, São Paulo, Séfer, 1997.

10 TEB - Tradução Ecumênica da Bíblia, São Paulo: Loyola, 2015.

11 Dicionário internacional de teologia do AT, São Paulo: Vila Nova, 1988.

12 Cesáreo de Arles, sermão 23. Liturgia das horas de segunda-feira, 17a Semana do Tempo Comum. 
salienta a misericórdia divina no cântico de Maria no Magnificat (Lc 1,50-54) e no cântico de Zacarias, onde a misericórdia é o escudo da aliança de Deus com o seu povo (Lc 1,72-78). Finaliza com a parábola do bom samaritano onde o doutor da lei é forçado a proclamar: "É aquele que agiu com misericórdia" (Lc 10,29-37).

Segundo Pe. Ney, no evangelho de João não identificamos a palavra misericórdia, substituindo éleos por ágape (amor) ou cháris (graça). Ao final, para João, "Deus é amor" (1Jo 4,8-16) e, como tal, é misericórdia e quer de nós o mesmo sentimento e atitude. Enfim, o "único mandamento" de Jesus, o Filho de Deus, é que pratiquemos o amor fraterno (Jo 13,34 e 15,12).

Nos seus escritos São Paulo declara que somos vasos de misericórdia. Mas a profecia de Oseias (Os 12,1-3) se realiza plenamente em Jesus que revelou toda a misericórdia do Pai. ${ }^{13}$ Reafirma Paulo que Deus é rico em misericórdia $(\mathrm{Ef} 2,4)$ e realiza misericórdia em favor de Onesiforo (2Tm 1,16-18). Assim é clássica e teologicamente profunda a afirmação da Carta aos Hebreus: "Aproximemo-nos confiantes do trono da graça, para conseguirmos misericórdia e alcançar as graças e o auxílio oportuno" (Hb 4,16).

No contexto musical, Pe. Ney revela sua profunda cristologia, manifesta em suas músicas e textos exegéticos. Assim, identifica na Carta de Pedro a misericórdia manifesta pela ressureição de Jesus Cristo (1Pd 1,3), acrescentando a Carta de Judas que nos situa na esperança da misericórdia de Nosso Senhor Jesus Cristo (Jd 21,22). Arremata, finalmente, com o forte texto de Tiago onde se proclama o triunfo da misericórdia sobre o julgamento divino (Tg 2,12-13), desde que não haja discriminação de pessoas e desprezo dos pobres. A palavra de Jesus garante liberdade diante do pecado e da lei pela prática do amor. Daí que o juízo é sem misericórdia para quem não praticou misericórdia. Mas Deus não se deixa vencer e, por isso, a misericórdia desdenha o julgamento. Como deseja São João: “A vitória da fé venceu o mundo" (1Jo 5,4).

Finaliza Pe. Ney sua teologia da misericórdia reafirmando com Tiago que a "religião pura e sem mancha diante de Deus Pai é esta: assistir os órfãos e viúvas em suas tribulações e guardar-se livre da corrupção do mundo" (Tg 1,27).

13 Vide Ney Brasil Pereira, em Encontros Teológicos, número 4 (2008/1, p. 149-163). 
Conclui Padre Ney magistralmente: "a religião tem uma vertente ritual e uma vertente ética; se a vertente ritual distingue as religiões, a vertente ética as une e identifica no compromisso de amor, bondade e misericórdia em favor dos excluídos! De que adiantam nossos belos hinos e liturgias sem a expressão concreta da eticidade? 'Eu quero misericórdia e não rito' está nos interpelando sempre!"14

\section{Conclusão}

Vimos neste artigo um perfil da rica personalidade de Pe. Ney Brasil Pereira e sua paixão pelo princípio misericórdia. Podemos constatar esse amor apaixonado e misericordioso refletido por décadas na pastoral carcerária na Arquidiocese de Florianópolis e no âmbito do Regional Sul IV da CNBB. Contou nesta experiência com pessoas heroicas que marcaram época e muitos agentes de pastoral que solidificaram este campo pastoral.

A misericórdia do coração desse presbítero transbordava no atendimento aos pobres (muitos ex-presidiários) que corriam ao ITESC e à FACASC, para encontrarem no "pai dos pobres" a acolhida, a palavra orientadora e a ajuda possível para as suas mazelas. Não foram poucas as incompreensões sofridas no exercício desse ministério. Todavia sua resistência e persistência merecem a admiração de muitos e, com certeza, a coroa da vida!

14 Ver entrevista de Ney Brasil Pereira em IHU - online, em 24/07/2014. 